\title{
Breast Conservative Surgery for Breast Cancer: Indian Surgeon's Preferences and Factors Influencing Them
}

\section{Rohini Dutta}

Christian Medical College and Hospital Ludhiana

\section{Sargun Virk}

Sri Guru Ram Das Institute of Medical Sciences and Research

\section{Priti Patil}

WHO Collaborating Centre for Research in Surgical Care Delivery in Low-Middle-Income Countries, Mumbai, India

\section{Geetu Bhandoria}

WHO Collaborating Centre for Research in Surgical Care Delivery in Low-Middle-Income Countries, Mumbai, India

\section{Bhakti Sarang}

WHO Collaborating Centre for Research in Surgical Care Delivery in Low-Middle-Income Countries.

Mumbai, India

\section{Anshul Mahajan}

Government Medical College Amritsar

\section{Monty Khajanchi}

WHO Collaborating Centre for Research in Surgical Care Delivery in Low-Middle-Income Countries,

Mumbai, India

\section{Samarvir Jain}

Dayanand Medical College and Hospital

\section{Lovenish Bains}

Maulana Azad Medical College

\section{Prashant Bhandarkar}

WHO Collaborating Centre for Research in Surgical Care Delivery in Low-Middle-Income Countries, Mumbai, India

\section{Shamita Chatterjee}

Seth Sukhlal Karnani Memorial Hospital: Institute of Postgraduate Medical Education and Research Nobhojit Roy ( $\square$ nobsroy@gmail.com )

Karolinska Institutet https://orcid.org/0000-0003-2022-7416

\section{Anita Gadgil}


WHO Collaborating Centre for Research in Surgical Care Delivery in Low-Middle-Income Countries, Mumbai, India

\section{Research}

Keywords: Breast conservative surgery, mastectomy, breast cancer, cancer surgery, India

Posted Date: November 15th, 2021

DOI: https://doi.org/10.21203/rs.3.rs-1052407/v1

License: (c) (1) This work is licensed under a Creative Commons Attribution 4.0 International License. Read Full License 


\section{Abstract}

Background: It is well established that disease-free survival and overall survival after breast conservation surgery (BCS) followed by radiotherapy are equivalent to that after mastectomy. However, in Asian countries, the rate of BCS continues to remain low. The cause may be multifactorial including the patient's choice, availability and accessibility of infrastructure and surgeon's choice. We aimed to elucidate the Indian surgeons' perspective while choosing between BCS and mastectomy, in women oncologically eligible for BCS.

Methods: We conducted a survey-based cross-sectional study over 3 weeks between January-February 2021. Indian surgeons with general surgical or specialised onco-surgical training, who consented to participate were included in the study. Multinomial logistic regression was performed to assess the effect of study variables on offering mastectomy or BCS to an eligible patient.

Results: A total of 347 responses were included. The mean age of the participants was 43(11) years. $63 \%$ of the surgeons were in the $25-44$ years age group with the majority $(80 \%)$ being males. $66.4 \%$ of surgeons 'almost always' offered BCS to oncologically eligible patients. Surgeons who had undergone specialised training in oncosurgery or breast conservation surgery were 35 times more likely to offer BCS $(p<0.01)$. Surgeons working in hospitals with in-house radiation oncology facilities were 9 times more likely to offer BCS $(p<0.05)$. Surgeons' years of practice, age, sex and hospital setting did not influence the surgery offered.

Conclusion: Our study found that two-thirds of Indian surgeons preferred BCS over mastectomy. Lack of radiotherapy facilities and specialised surgical training were deterrents to offering BCS to eligible women.

\section{Introduction}

Breast cancer is the most common malignancy among women in India and around the world. $(1,2)$ In the year 2020, 178,361 new cases and 90,408 fatalities were attributed to breast cancer in India. (2) By 2025, breast cancer is projected to make up $15 \%$ of the nation's total cancer burden. $(3,4)$ Over decades, the standard surgical procedure to treat breast malignancy has been modified radical mastectomy (MRM). More recently, breast conservative surgery (BCS) with radiotherapy has gained widespread acceptance in the treatment of breast cancer all over the world. With advancements in surgical techniques, oncoplastic procedures and radiation therapy technology, survival rates after BCS followed by radiotherapy have been found to be equivalent to mastectomy, making breast cancer treatment less mutilating and cosmetically more acceptable for women. $(3,4)$ Despite this, the rate of BCS has been relatively low in Asian countries. (5) While the United States of America reported $64.5 \%$ of women with early-stage breast cancer undergoing BCS, $31 \%$ of breast carcinoma patients in Singapore underwent BCS. $(6,7)$ In India, only $11.3 \%$ of the patients who were offered BCS, underwent the procedure. (8) 
The strikingly low rates of BCS in low-and-middle-income countries (LMICs), including India, is because the majority of breast carcinoma cases are being detected at advanced stages as compared to highincome countries (HICs). $(9,10,11,12)$ Several infrastructure-related factors (availability and accessibility and affordability), shortage of surgeons with specialised BCS training, patient concerns about recurrence and radiation have also been documented to contribute to the preference of mastectomy over BCS. $(8,13,14)$ Adjuvant radiotherapy facilities and multidisciplinary teams predominantly are concentrated in urban areas leading to resource mismatch. (14) Further, 75\% of cancer costs in India are out-of-pocket expenditures which contribute to delayed diagnosis and treatment. (13) Mandatory addition of adjuvant radiotherapy to BCS adds to this burden.

In Asia, although treatment options are discussed with patients, it is seen that the treatment decision is significantly based on the surgeon's recommendations. (15) Even in tertiary care centres, the surgeon is documented as an independent determinant for mastectomy. (16) Therefore, understanding the factors that influence the treating surgeon's choice of surgery is very important. There is a paucity of data on the factors that affect providers' decisions in India. Thus, we conducted this study to elucidate the Indian surgeons' choice of surgical treatment between BCS and mastectomy in oncologically eligible women. (17)

\section{Methodology}

\section{Study Design}

We conducted a cross-sectional survey among surgeons practising in India, to assess their perception about choosing BCS and MRM in treating patients with breast cancer for 3 weeks between JanuaryFebruary 2021.

\section{Development and Pretesting}

The survey was developed by a research consortium 'IndSurg' constituting practising surgeons and medical students; initiated by the WHO Collaborating Centre for Research in Surgical Care Delivery in LMICs, Mumbai, India. The survey was designed in the English language and questions were tested through a series of pilot surveys for unbiased intents and ambiguity. Data variables were chosen to include factors addressed in the literature and were objective, easily standardised and relevant to minimise missing data and maximise data quality. The survey was strictly anonymised and no identifying data were collected.

The survey had three sections. The first section included questions about surgeons' demographics, educational qualifications, area of expertise, training in oncosurgery, and whether they practised in public (free service) or private (fee for service) hospitals. $(18,19)$ The second section enquired about the breast cancer work volumes, and whether they offer BCS or MRM in women who are oncologically eligible to receive breast conservation surgery. (20) The third section included reasons, if any, for choosing MRM over BCS, in patients who are eligible for breast conservation. This section included factors that would 
influence the surgeons' decisions based on patient population, radiotherapy facilities available in the area of practice and their training and ability to perform BCS.

\section{Data Collection}

This was an open (open access to anybody with the survey link) self-administered survey administered via 'Google Forms' that automatically captured the data. The survey link was circulated in various surgical groups on social media and email lists of professional associations and societies of surgeons and surgical oncologists. Survey link responses were active for 3 weeks between January 2021 and February 2021. Participation in the survey was voluntary after agreeing to consent to participate. No reminder emails and messages were sent to the participants. Surgeons who had either completed a masters degree in general surgery or underwent oncosurgical training during or following their masters in general surgery, and were practising in India were included in the study. Surgeons who did not consent to participate or are not performing any breast cancer surgery were excluded from the study. Participation in the survey was voluntary, without any incentive for participation.

\section{Statistical analysis}

Data were analysed using SPSS Version 24 and Microsoft Excel 2019. Descriptive statistics for overall study participants were presented as absolute numbers and percentages of the group. Multinomial logistic regression was performed to assess the effect of study variables on offering BCS to an eligible patient. A p-value of less than 0.05 was considered statistically significant.

\section{Results}

A total of 351 responses were received at the end of the study period. Four surgeons did not perform breast surgery as a part of their clinical practice, so were excluded from further analyses yielding a final sample of 347 respondents. Since the survey was circulated through multiple platforms, we were unable to calculate a response rate.

\section{Participant Characteristics}

The mean age of the study participants was $43(11)$ years with $63.1 \%$ of the participants in the $25-44$ years age group. The majority of participants $(80.5 \%)$ were males. $59.8 \%$ had received specialised oncosurgical training. A quarter $(25.6 \%)$ of the study participants reported that they were practising breast surgery for the last 20 years or more and 137 (42.2\%) surgeons mentioned that they perform more than ten breast cancer surgeries in a month as a lead surgeon (Table 1). Of the 207 participants with oncosurgical training, 191 had done a fellowship or masters course in oncosurgery and 16 had BCS training as a part of their masters/residency training in general surgery. 
Table 1

Participant Characteristics

\begin{tabular}{|c|c|c|}
\hline Variable & $N=347$ & $\%$ \\
\hline Age, years: mean \pm SD (range) & $43 \pm 11$ & $(25-83)$ \\
\hline \multicolumn{3}{|l|}{ Age Group (Years) } \\
\hline $25-34$ & 90 & $25.9 \%$ \\
\hline $35-44$ & 129 & $37.2 \%$ \\
\hline $45-54$ & 71 & $20.5 \%$ \\
\hline $55-64$ & 41 & $11.8 \%$ \\
\hline$>=65$ & 16 & $4.6 \%$ \\
\hline \multicolumn{3}{|l|}{ Sex of participant } \\
\hline Male & 276 & $80.5 \%$ \\
\hline Female & 67 & $19.5 \%$ \\
\hline \multicolumn{3}{|l|}{ Details of surgical training } \\
\hline Surgeons with Oncosurgery training & 207 & $59.8 \%$ \\
\hline Masters in General Surgery & 139 & $40.2 \%$ \\
\hline \multicolumn{3}{|l|}{ Setting of practice } \\
\hline Private & 194 & $56.1 \%$ \\
\hline Public & 152 & $43.9 \%$ \\
\hline \multicolumn{3}{|l|}{ Level of institution } \\
\hline Tertiary Hospital & 303 & $88.1 \%$ \\
\hline Secondary Hospital & 41 & $11.9 \%$ \\
\hline \multicolumn{3}{|l|}{ Duration of surgical practice (Years) } \\
\hline$<10$ & 150 & $43.5 \%$ \\
\hline $10-20$ & 106 & $30.7 \%$ \\
\hline$>20$ & 89 & $25.8 \%$ \\
\hline \multicolumn{3}{|c|}{ The volume of breast cancer surgeries in your practice per month as a lead surgeor } \\
\hline$<10$ Surgeries & 188 & $57.8 \%$ \\
\hline$\geq 10$ Surgeries & 137 & $42.2 \%$ \\
\hline
\end{tabular}




\begin{tabular}{|c|c|c|}
\hline Variable & $\mathrm{N}=347$ & $\%$ \\
\hline Same Institute & 209 & $60.8 \%$ \\
\hline Not in the same institute but in the same city & 128 & $36.8 \%$ \\
\hline How likely are you to offer BCS to an eligible woman? & & \\
\hline Almost always & 229 & $66.4 \%$ \\
\hline Occasionally & 91 & $26.4 \%$ \\
\hline Almost never & 25 & $7.2 \%$ \\
\hline
\end{tabular}

Two-thirds (66.4\%) of the surgeons almost always offered BCS to every eligible woman (Table 1). Various reasons for not offering BCS were expressed by the surgeons, even if the woman was oncologically eligible for BCS (Table 2).

Table 2

Reason for choosing mastectomy over BCS

\begin{tabular}{|lll|}
\hline Choosing MRM over BCS reason & $\mathbf{N}=\mathbf{2 6 1}$ & $\%$ \\
\hline My patients may not follow up for radiation after surgery & 109 & $31.4 \%$ \\
\hline My patients cannot afford BCS and adjuvant radiation & 61 & $17.6 \%$ \\
\hline Believe mastectomy is an oncologically safer option & 42 & $12.1 \%$ \\
\hline No radiotherapy facilities where I practice & 24 & $6.9 \%$ \\
\hline I lack the training or expertise to perform BCS & 20 & $5.7 \%$ \\
\hline No mammography facility where I practice & 5 & $1.4 \%$ \\
\hline
\end{tabular}

\section{*Numbers \& percentages may not add up due to multiple reasons given by many surgeons}

\section{Factors associated with surgeons' decision on treatment}

Multinomial logistic regression was used to predict the independent factors that would decide the type of surgery from the surgeon's perspective (Table 3). The relationship between dependent variables (offering BCS to an eligible woman) was probed by considering the 'almost never offering BCS' as a reference category. Surgeons with specialized oncosurgical training had significantly higher chances of offering BCS than general surgeons (occasionally offering BCS OR 8.27 $p=0.059$ and almost always offering BCS OR 35.24, $p=0.001$ ). There was no association of the surgeons' demographic details (age, sex), and years of practice on their preference of surgical procedure. Surgeons demonstrated seven and nine-times higher 
odds of 'occasionally' and 'almost always' offering BCS respectively if the radiation oncology facility was available in the same institute $(\mathrm{OR}=7.488, \mathrm{p}=0.044, \mathrm{OR}=9.655, \mathrm{p}=0.025)$ 
Table 3

Multinomial Logistic Regression - How likely are surgeons to offer BCS to an eligible woman*

\section{Narration}

\section{Almost Occasional \\ Never}

(Referent

category)
Almost Always

\begin{tabular}{|c|c|c|c|c|c|}
\hline n & $\mathrm{n}$ & $\begin{array}{l}\text { Odds Ratio } \\
\text { (95\% Cl) }\end{array}$ & $\begin{array}{l}\mathrm{p} \text { - } \\
\text { value }\end{array}$ & $\mathrm{n}$ & $\begin{array}{l}\text { Odds } \\
\text { Ratio } \\
(95 \% \mathrm{Cl})\end{array}$ \\
\hline
\end{tabular}

Age group (Years) $(\mathrm{N}=345)$

\begin{tabular}{|c|c|c|c|c|c|c|c|}
\hline $25-34$ & 9 & 26 & $\begin{array}{l}0.314 \\
(0.006- \\
15.232)\end{array}$ & 0.559 & 54 & $\begin{array}{l}0.211 \\
(0.004- \\
10.605)\end{array}$ & 0.436 \\
\hline $35-44$ & 5 & 34 & $\begin{array}{l}0.5(0.013- \\
19.143)\end{array}$ & 0.709 & 89 & $\begin{array}{l}0.218 \\
(0.005- \\
8.694)\end{array}$ & 0.418 \\
\hline $45-54$ & 5 & 19 & $\begin{array}{l}0.539 \\
(0.029- \\
9.903)\end{array}$ & 0.677 & 47 & $\begin{array}{l}0.303 \\
(0.016- \\
5.746)\end{array}$ & 0.427 \\
\hline $55-64$ & 4 & 8 & $\begin{array}{l}0.436(0.03 \\
-6.332)\end{array}$ & 0.543 & 29 & $\begin{array}{l}0.641 \\
(0.045- \\
9.134)\end{array}$ & 0.743 \\
\hline$>=65$ & 2 & 4 & Referent Cat & gory & 10 & Referent & egory \\
\hline \multicolumn{8}{|c|}{ Sex of participant $(\mathrm{N}=341)$} \\
\hline Female & 5 & 17 & $\begin{array}{l}1.558 \\
(0.351- \\
6.917)\end{array}$ & 0.56 & 45 & $\begin{array}{l}1.615 \\
(0.36- \\
7.243)\end{array}$ & 0.531 \\
\hline Male & 20 & 72 & Referent Cat & gory & 182 & Referent & egory \\
\hline
\end{tabular}

\section{Details of surgical training ( $\mathrm{N}=344)$}

\begin{tabular}{|c|c|c|c|c|c|}
\hline $\begin{array}{l}\text { Surgeons with Oncosurgery } \\
\text { training }\end{array}$ & 32 & $\begin{array}{l}8.273 \\
(0.927- \\
73.845)\end{array}$ & 0.059 & 173 & $\begin{array}{l}35.236 \\
(4.059- \\
305.862)\end{array}$ \\
\hline
\end{tabular}

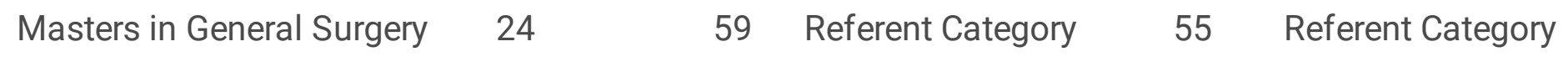

\section{Practice Center $(\mathrm{N}=344)$}

\begin{tabular}{|c|c|c|c|c|c|c|c|}
\hline Public & 14 & 53 & $\begin{array}{l}1.033 \\
(0.328- \\
3.252)\end{array}$ & 0.955 & 83 & $\begin{array}{l}0.49 \\
(0.153- \\
1.564)\end{array}$ & 0.228 \\
\hline Private & 11 & 38 & Referent & gory & 145 & Referent & tegory \\
\hline
\end{tabular}

* Two participants have not responded to the offering of BCS question, those were not considered in the multinomial logistic regression analysis 


\section{Narration}

Almost

Never

(Referent

category)
Occasional

Almost Always

Center Level $(\mathrm{N}=342)$

Tertiary Hospital

19

$80 \quad 0.814$

$(0.177-$

$0.791 \quad 202$

0.993

3.739)

(0.209 -

4.724)

0.993

Secondary Hospital

6

11 Referent Category

24 Referent Category

Duration of practising surgery ( $\mathrm{N}=343$ )

$<10$ Years

10

$43 \quad 3.69(0.212$

$0.371 \quad 95$

3.213

(0.182 -

0.425

$-64.352)$

56.684)

\begin{tabular}{|c|c|c|c|c|c|c|}
\hline 10-20 Years & 6 & 26 & $\begin{array}{l}1.039 \\
(0.134 \\
8.035)\end{array}$ & 0.971 & 74 & $\begin{array}{l}0.873 \\
(0.111- \\
6.866)\end{array}$ \\
\hline
\end{tabular}

$>20$ Years

8

21 Referent Category

60

Referent Category

The volume of breast cancer surgeries performed in a month as a lead surgeon $(\mathrm{N}=323)$

\begin{tabular}{|c|c|c|c|c|c|c|}
\hline$<10$ Surgeries & 19 & 66 & $\begin{array}{l}0.961 \\
(0.174 \\
5.321)\end{array}$ & 0.964 & 103 & $\begin{array}{l}0.443 \\
(0.083- \\
2.366)\end{array}$ \\
\hline
\end{tabular}

$>=10$ Surgeries

2

21 Referent Category

112 Referent Category

Distance to the radiation oncology facility from institute/place of practice $(\mathrm{N}=337)$

Same Institute

5

$49 \quad 7.488$

0.04

$(1.059-$

52.936)

9.655

$(1.325$

0.025

0.897

52.936)

Not in the same institute $\quad 14$

but in same city $<2$ hours

14

$\begin{array}{ll}31 & 1.637(0.33 \\ & -8.135)\end{array}$

$0.547 \quad 64$

70.374)

In same city $>2$ hours

5

7 Referent Category

9

1.724

$(0.329-$

0.52

9.043)

* Two participants have not responded to the offering of BCS question, those were not considered in the multinomial logistic regression analysis 


\section{Discussion}

Our study explored the Indian surgeons' perspective while offering BCS to oncologically eligible women. It was seen that $66.4 \%$ of surgeons almost always offered BCS to oncologically eligible women. Specialised surgical training and distance of the radiation oncology facility from the surgeon's institute were the independent determinants for choosing BCS over mastectomy.

Our study highlighted that surgeons with oncosurgical training almost always offered BCS to oncologically eligible patients. This was similar to studies from India $(p<0.01)$ and China $(p=0.003)$ which found that surgeons with super speciality surgical training were performing BCS more frequently compared to general surgeons and were independent predictors of BCS. $(8,21)$ In contrast, a study from the USA reports that surgical oncologists were more likely to perform mastectomy over BCS. However, it was also reported that this could be a reflection of the fact that they treat more complicated patients. (22)

The perceived inability of patients to follow up for adjuvant radiotherapy was cited as one of the commonest reasons for not offering BCS in our study. Surgeons were nine times more likely to almost always offer BCS to patients if radiotherapy facilities were available in the same institute compared to if the radiation facility was within the same city more than 2 hours away $(p=0.01)$. A similar trend was seen in a study from the USA where the likelihood of BCS increased when a radiation facility was available in the same hospital. (23) The study also demonstrated that women who underwent BCS were less compliant to the use of adjuvant radiation therapy if they lived greater distances ( $\geq 40$ miles) from a centre with a radiation facility. This is also in concordance with a study from Iran where the nonavailability of adjuvant radiotherapy facilities was cited as one of the reasons for surgeons not recommending BCS to their patients. (24) This highlights that access to adjuvant radiotherapy services is a major determinant of BCS and warrants prioritisation of investment in radiotherapy facilities to increase its access and affordability.

In North America, female surgeons were found more likely to offer BCS, as they were supposedly able to alleviate patients' concerns regarding BCS better in comparison to their male counterparts. (25) Female surgeons were twice more likely to offer BCS than males as shown in an analysis by Hershman et al in patients with early-stage breast cancer. (26) However, our study did not show any variation in the outlook towards BCS according to surgeons' sex or age. This was similar to another study from India done by Bothra et al. (19) We did not find a statistically significant association between surgeons' years of experience with their decision to offer BCS. Conversely, Bothra et al. highlighted that Indian surgeons during the early part of their career (age group of 20-30 years) preferred to perform mastectomy over BCS due to the perceived fear of tarnishing reputation in case of failure of treatment. Senior surgeons (age $>50$ years) preferred to perform mastectomy due to their lack of training in BCS. (19) Arnaud et al. also found that patients treated by older surgeons underwent mastectomy more often. (27)

Our study has a large sample size and a good representation of participating surgeons across age and years in practice. However, it has several limitations. $81 \%$ of the participants included in our study practised in tertiary care centres whereas the majority of the breast cancer surgeries are performed by the 
general surgeons at secondary level hospitals or private hospitals, in India. Similarly, rural areas where $70 \%$ of India's population resides, may not have surgeons trained in BCS or access to radiotherapy. This survey thus may under-represent the surgeons of rural areas, private hospitals and smaller setups where significant volumes of breast surgeries are performed. (14) However, it does provide insight into why surgeons may hesitate to offer BCS to eligible women.

A surgeons' intent to impart appropriate quality of treatment and improved quality of life for the patient is essential for performing BCS in an eligible patient. (8) Therefore, general surgeons with less exposure to BCS training need to be trained in performing BCS and in counselling patients. This can occur through the inculcation of training in BCS as a part of general surgical training. Higher fellowships or specialised oncosurgical training after completion of masters in general surgery will always remain an option for a section of surgeons. Previous studies from Hong Kong and Malaysia have found that most patients follow their surgeon's recommendations in deciding between mastectomy and BCS. $(28,29)$ This makes it essential for patients with breast cancer to be informed of all their treatment options by the surgeons, to make an informed surgical decision. This can be supported through the implementation of shared decision-making tools, which have been shown to increase the rate of BCS. $(30,31)$

The data from our study shows that the majority of surgeons offer BCS to eligible patients. However, it's observed that a significant number of women who could be candidates for BCS still decide to undergo mastectomy. (14) Hence, larger-scale studies analysing and documenting the effect of multiple factors must be conducted to understand surgical care for breast cancer in India. Future work should focus on identifying intricate barriers pertaining to access and availability of radiation treatments that may influence patients' choice of BCS. $(8,24)$

\section{Conclusion}

We found that two-thirds of Indian surgeons prefer BCS over mastectomy. This is consistent with global trends. Lack of surgeons trained in performing BCS was a common deterrent to offering BCS. This requires scaling of training opportunities in BCS for general surgeons. Availability of a radiation facility in the same institute as the treating surgeon was the top most determinant in surgeons offering BCS to oncologically eligible patients. Investment in radiotherapy facilities to increase access and affordability must be prioritised to further increase BCS rates in India.

\section{Abbreviations}

- BCS- Breast Conservative Surgery

- MRM- Modified Radical Mastectomy

\section{Declarations}


Ethics approval and consent to participate: Institutional Ethics Committee approval was taken from Terna Medical College, Mumbai, Maharashtra, India. (TMCHRC/SURG2021/IEC protocol-13/54). All participants consented to take part in the study.

Consent for publication: Not Applicable

Availability of data and materials:The dataset generated and analysed during the current study are available from the corresponding author on reasonable request.

Competing interests: The authors declare that they have no competing interests.

Funding: This work did not receive any funding.

Authors' contributions: AG,RD, SV, PP, GB, BS, MK, LB, NR conceptualised the study. RD, SV, PP, GB, BS, MK, $L B, A G$ were involved in data collection and analysis. RD, SV, PP, BS, PB, AG were involved in the literature review and writing of the manuscript. $B S, S J, A M, M K, L B, G B, S C, P B, N R, A G$ critically reviewed the manuscript.

Acknowledgements: Our study team sincerely acknowledges the support of Dr C.S Pramesh, Tata Memorial Hospital, Mumbai and member participants of the National Cancer Grid for their participation in the survey.

\section{References}

1. Cancer. World Health Organization. https://www.who.int/news-room/fact-sheets/detail/cancer. Accessed August 2021.

2. The global cancer observatory. (2021). India Globocan 2020 [Fact Sheet]. International Agency for Research on Cancer. https://gco.iarc.fr/today/data/factsheets/populations/356-india-factsheets.pdf. Accessed August 2021.

3. van Maaren M, de Munck L, de Bock G, Jobsen J, van Dalen T, Linn S et al. 10 year survival after breast-conserving surgery plus radiotherapy compared with mastectomy in early breast cancer in the Netherlands: a population-based study. The Lancet Oncology. 2016;17(8):1158-1170.

4. Veronesi U, Cascinelli N, Mariani L, Greco M, Saccozzi R, Luini A et al. Twenty-Year Follow-up of a Randomized Study Comparing Breast-Conserving Surgery with Radical Mastectomy for Early Breast Cancer. New England Journal of Medicine. 2002;347(16):1227-1232.

5. Sinnadurai S, Kwong A, Hartman M, Tan E, Bhoo-Pathy N, Dahlui M et al. Breast-conserving surgery versus mastectomy in young women with breast cancer in Asian settings. BJS Open. 2018;3(1):4855.

6. Kummerow K, Du L, Penson D, Shyr Y, Hooks M. Nationwide Trends in Mastectomy for Early-Stage Breast Cancer. JAMA Surgery. 2015;150(1):9. 
7. Teo SY, Chuwa E, Latha S, Lew YL, Tan YY. Young breast cancer in a specialised breast unit in Singapore: clinical, radiological and pathological factors. Annals of the Academy of Medicine of Singapore. 2014;43:79-85.

8. Bothra S, Sabaretnam M, Chand G, Mishra A, Agarwal G, Agarwal A. Indian Surgeons' Perspective Regarding Breast-Conserving Surgery: A Cohort Study. International Journal of Molecular \& Immuno Oncology. 2019;4:72-81.

9. Carlson R, Anderson B, Chopra R, Eniu A, Jakesz R, Love R et al. Treatment of Breast Cancer in Countries with Limited Resources. The Breast Journal. 2003;9(s2):S67-S74.

10. Rivera-Franco M, Leon-Rodriguez E. Delays in Breast Cancer Detection and Treatment in Developing Countries. Breast Cancer: Basic and Clinical Research. 2018;12:117822341775267.

11. Yeole BB, Kumar AVR, Kurkure A, Sunny L. Population-based survival from cancers of breast, cervix and ovary in women in Mumbai, India. Asian Pac J Cancer Prev. 2004;5(3):308-15.

12. Walters $\mathrm{S}$, Maringe $\mathrm{C}$, Butler $\mathrm{J}$, Rachet $B$, Barrett-Lee $\mathrm{P}$, Bergh $\mathrm{J}$ et al. Breast cancer survival and stage at diagnosis in Australia, Canada, Denmark, Norway, Sweden and the UK, 2000-2007: a populationbased study. British Journal of Cancer. 2013;108(5):1195-1208.

13. Pramesh C, Badwe R, Borthakur B, Chandra M, Raj E, Kannan T et al. Delivery of affordable and equitable cancer care in India. The Lancet Oncology. 2014;15(6):e223-e233.

14. Chatterjee S. Is India Overdoing Mastectomy?. Indian Journal of Surgery. 2020;.

15. Galeano Machuca M, Cheng S, Jou T, Cheng C. Determinants of Breast-Conserving Therapy in the Asian Population: A Systematic Review. World Journal of Surgery. 2020;45(3):799-807.

16. Reitsamer R, Menzel C, Glueck S, Hitzl W, Peintinger F. Predictors of Mastectomy in a Certified Breast Center The Surgeon is an Independent Risk Factor. The Breast Journal. 2008;14(4):324-329.

17. Raina V, Bhutani M, Bedi R, Sharma A, Deo SV, Shukla NK et al. Clinical features and prognostic factors of early breast cancer at a major centre in North India. Indian J Cancer. 2005;42:36-41.

18. Bajpai V. The Challenges Confronting Public Hospitals in India, Their Origins, and Possible Solutions. Advances in Public Health. 2014;2014:1-27.

19. Berman P, Ahuja R, Bhandari L. The impoverishing effect of healthcare payments in India: New methodology and findings. Econ Polit Wkly. 2010;45(16):65-71.

20. Cardoso F, Fallowfield L, Costa A, Castiglione M, Senkus E. Locally recurrent or metastatic breast cancer: ESMO Clinical Practice Guidelines for diagnosis, treatment and follow-up. Annals of Oncology. 2011;22:vi25-vi30.

21. Woon Y, Chan M. Breast conservation surgery-the surgeon's factor. The Breast. 2005;14(2):131-135.

22. Boero IJ, Paravati AJ, Hou J, Gillespie EF, Schoenbrunner A, Unkart J, et al. The impact of surgeons on the likelihood of mastectomy in breast cancer. Annals of Surgery. 2019;269(5):951-8.

23. Bellavance EC, Kesmodel SB. Decision-making in the surgical treatment of breast cancer: Factors influencing women's choices for mastectomy and breast conserving surgery. Frontiers in Oncology. $2016 ; 6$. 
24. Najafi M, Ebrahimi M, Kaviani A, Hashemi E, Montazeri A. Breast conserving surgery versus mastectomy: Cancer practice by general surgeons in Iran. BMC Cancer. 2005;5(1).

25. Gu J, Groot G, Boden C, Busch A, Holtslander L, Lim H. Review of factors influencing women's choice of mastectomy versus breast conserving therapy in early stage breast cancer: A systematic review. Clinical Breast Cancer. 2018;18(4).

26. Hershman DL, Buono D, Jacobson JS, McBride RB, Tsai WY, Joseph KA, et al. Surgeon characteristics and use of breast conservation surgery in women with early stage breast cancer. Annals of Surgery. 2009;249(5):828-33.

27. Arnaud S, Houvenaeghel G, Moutardier V, Butarelli M, Martino M, Tallet A, et al. Patients' and surgeons' perspectives on axillary surgery for breast cancer. European Journal of Surgical Oncology (EJSO). 2004;30(7):735-43.

28. Lam WWT, Fielding R, Ho EYY, Chan M, Or A. Surgeon's recommendation, perceived operative efficacy and age dictate treatment choice by Chinese women facing breast cancer surgery. Psycho-Oncology. 2005;14(7):585-93.

29. Teh Y-C, Shaari NEN, Taib NA, Ng C-H, See M-H, Tan G-H, et al. Determinants of Choice of Surgery in Asian Patients with Early Breast Cancer in A Middle Income Country. Vol. 15, Asian Pacific Journal of Cancer Prevention. Asian Pacific Organization for Cancer Prevention; 2014. p. 3163-7. http://dx.doi.org/10.7314/APJCP.2014.15.7.3163

30. Savelberg W, Moser A, Smidt M, Boersma L, Haekens C, Weijden Tv. Protocol for a preimplementation and post-implementation study on shared decision-making in the surgical treatment of women with early-stage breast cancer. BMJ Open. 2015;5(3).

31. Whelan T, Levine M, Willan A, Gafni A, Sanders K, Mirsky D, et al. Effect of a decision aid on knowledge and treatment decision making for breast cancer surgery. JAMA. 2004;292(4):435. 